\title{
Etnogeomorfologia, uma possibilidade didática no ensino de Geomorfologia
}

\author{
Ethnogeomorphology, a pedagogical possibility in geomorphology teaching
}

\author{
Bruno Ferreira \\ Professor Adjunto - IGDEMA/UFAL, Brasil \\ brunge2005@gmail.com
}

Thiago Cavalcante Lins Silva Mestrando em Geografia - PPGG/UFAL, Brasil

thiago0_lins@hotmail.com

Andrei Gomes de Azevedo Mestrando em Educação - PPGE/UFRN, Brasil ndrei.g.azevedo@hotmail.com

\author{
Davi Almeida Pinheiro \\ Graduado em Geografia - UFRN, Brasil \\ davisbpb@hotmail.com
}

\begin{abstract}
Resumo
A partir da segunda metade do século XX, começou-se a utilizado a terminologia "etnociência" para designar conhecimentos de populações tradicionais e suas classificações a respeito dos fenômenos naturais. A popularização da etnociência permitiu a ação de várias disciplinas e áreas do conhecimento científico, interessando-se pelo conhecimento dos povos tradicionais e conectando-os a seus conhecimentos acadêmicos. A Geomorfologia, por apresentar íntima relação com o ser humano em seu cotidiano, possibilita o uso de ferramentas que aproximem a realidade do dia a dia das pessoas à linguagem científica, o que acabou por se denominar, a partir de estudos recentes, de "etnogeomorfologia". No entanto, é necessário que se reconheça o exercício educativo como sendo o elo mediador desta ligação, uma vez que o uso da etnogeomorfologia em sala de aula pode levar o aluno a uma aprendizagem significativa, considerando suas próprias experiências e ações. O presente trabalho propõe a utilização da etnogeomorfologia como uma possibilidade didática no ensino de Geomorfologia, na intenção de promover uma alternativa pedagógica que aproxime o conhecimento científico tradicional ao conhecimento popular e ao cotidiano das pessoas.
\end{abstract}

Palavras-chave: Ensino de Geomorfologia, Popularização da Ciência, Etnogeomorfologia.

\begin{abstract}
Since the second half of the twentieth century, the term "ethnoscience" has been used to designate knowledge of traditional populations and their classifications regarding natural phenomena. The popularisation of ethnoscience allowed the action of various disciplines and areas of scientific knowledge, taking an interest in the knowledge of traditional people and connecting them to their academic knowledge. The Geomorphology, since it has a close relationship with the human being in their daily lives, enables the use of tools that bring the everyday reality of people closer to the scientific language, what has been called, from recent studies, "ethnogeomorphology". However, it
\end{abstract}


is necessary to recognise the educational exercise as the mediator link of this connection, since the use of ethnogeomorphology in the classroom can lead the students to meaningful learning, considering their own experiences and actions. This paper proposes the use of ethnogeomorphology as a didactic possibility in the teaching of geomorphology, intending to promote a pedagogical alternative that brings traditional scientific knowledge closer to widespread knowledge and people's daily lives.

Keywords: Geomorphology Teaching, Popularization of Science, Ethnogeomorphology.

\section{INTRODUÇÃO}

Tendo em vista a necessidade de aprendizagem dos conhecimentos empíricos de determinados grupos culturais pela Ciência, algo que começou a ganhar destaque em estudos antropológicos no início da segunda metade do século XX, surge o termo "etnociência", com o intuito de estudar a organização classificatória e a nomenclatura dos organismos pelas comunidades tradicionais (DIEGUES, 2001).

A “etnociência” foi definida por Diegues (2001) como um enfoque científico que contribui para o estudo do conhecimento das populações "tradicionais", especificamente sobre os processos naturais, que, partindo da linguística, busca descobrir a lógica do conhecimento humano sobre o mundo natural, as taxonomias e classificações totalizadoras. Muitas disciplinas e áreas do conhecimento científico se interessaram, nas últimas décadas, pelo tema do "etno", buscando assim uma maior relação dos seus estudos com os saberes populares. As disciplinas ligadas à Biologia, por exemplo, mantêm, de forma mais significativa desde a segunda metade do século XX, uma íntima relação com o tema da etnociência (SILVA et al., 2010).

Um dos métodos de estudo para coleta de dados, amplamente utilizado, em abordagens etnocientíficas compreende a etnografia, iniciada a partir de estudos antropológicos, analisando comunidades tradicionais (MAIA, 2001). Partindo da análise etnográfica ao trabalhar a etnociência, Campos (2002) afirma que é necessário haver um esforço em eliminar nossas bagagens disciplinares e pré-conceitos em relação ao outro, além de não o entender a partir de uma ferramenta disciplinar nossa, embasada em nossas vivências e experiências de estudo. O autor afirma que as várias disciplinas que se utilizam do "etno" foca previamente no saber do outro, propondo em contrapartida uma "etnografia de saberes, técnicas e práticas". Questionamentos em torno desta proposta podem ser feitos se levarmos em consideração que a "etnografia" não objetiva diretamente contribuir com o benefício da sociedade em geral e nem da investigada, situando-se apenas no campo da descrição.

Os estudos do "etno" devem apresentar uma aproximação maior da realidade sociocultural dos povos inseridos nos trabalhos em questão. Caminho pelo qual é possível, o pesquisador, se despir de saberes e vivências prévia, com o intuito de colocar os sujeitos analisados e suas experiências no centro da discussão, valorizando as construções dos mesmos em meio a seus espaços vividos e 
experimentados ao longo da vida (MORENO; DAZA, 2015; RIBEIRO, 2016). Isso significa "nos desfazer de nossas bagagens disciplinares" formais, sem como isso, anular totalmente a identidade filosófica e leituras de quem analisa, levando em consideração os métodos científicos.

Ainda sobre a etnografia, Paradise (1994) concorda que a metodologia etnográfica não é a mesma entre todos os profissionais. A autora sustenta que, durante certo período, a etnografia servia para descrever - apenas — o que se estava estudando, sem uma base teórica de fundo. Esta característica tem sido alterada nas últimas décadas, dentro dos estudos ligados ao etno, sendo que boa parte dos trabalhos passam a adotar metodologias conectadas a áreas específicas dos estudos acadêmicos. Paradise (1994) ainda afirma que não são os costumes em si que interessam, mas sim os significados por trás da ação humana. Tal raciocínio fornece justificativa para a realização de estudos em vários campos do saber, uma vez que fortalece a escolha de uma base disciplinar a ser adotada num trabalho etnográfico.

As possibilidades e pluralidades que acompanham o "etno" já ocorridas em outras áreas das ciências naturais, a exemplo da Etnobiologia e da Etnoecologia, trazem à tona a oportunidade de discutir o "etno" na Geografia, mais especificamente na Geomorfologia, uma vez que o homem tradicional e as populações vivem em constante interação com as morfologias e processos geomorfológicos. Nessas vivências, vai criando classificações e nomeando de forma peculiar o relevo circundante (TOLEDO; BARRERA-BASSOLS, 2009; RIBEIRO et al., 2015). Percebendo estas relações, dos sujeitos e seus saberes sobre o relevo, alguns pesquisadores começaram a desenvolver estudos ligando a Geomorfologia aos conhecimentos populares, trazendo luz, nos meios científicos, sobre as nomenclaturas utilizadas.

No tocante a uma "etnogeomorfologia", trabalhos têm sido feitos, nos últimos anos, traçando esta ligação entre o conhecimento científico acadêmico de Geomorfologia e os saberes populares, do homem tradicional (LOPES; RIBEIRO, 2016). No tocante ao tema, podemos citar o estudo de Ribeiro (2012), que se preocupou em pesquisar e descrever como o homem rural sertanejo do Cariri Cearense nomeia o relevo e entende os processos geomorfológicos, de onde vêm e como usam tais saberes. Merece destaque também o trabalho de Wilcok (2013), que propões a etnogeomorfologia como uma conexão, ou, "sinergia” entre a Geografia Física e a Geografia Humana, uma vez que colabora para reconhecer as paisagens como entidades culturais e, ao mesmo tempo, "biofísicas".

A etnogeomorfologia, como campo científico híbrido, possui contribuições de diversas esferas do conhecimento além da Geomorfologia, integrando conhecimentos relativos à Pedologia, Antropologia e Ecologia em suas análises, com foco voltado a descrever as relações e conhecimentos do homem sobre a superfície terrestre e seus processos, agregando tanto fatos humanos como físicos, em outras palavras realizando uma análise cultural das paisagens (RIBEIRO et al., 2015; LOPES ; RIBEIRO, 2016). Por seu caráter agregador e multidisciplinar a etnogeomorfologia possui múltiplas 
aplicações e potencialidades contribuindo tanto para atividades de gestão e planejamento como atividades educacionais (Fig. 01).

O presente estudo foi construído com o intuito de promover uma discussão sobre alternativas pedagógicas que facilitem a aprendizagem do aluno no tocante ao relevo, tornando esta aprendizagem significativa. É chamada "aprendizagem significativa" aquela que acontece ao se incorporar novas informações a elementos dos conhecimentos pré-existentes e relevantes na estrutura cognitiva dos alunos (CASTELLAR, 2005). Estas informações ganham novos significados quando ocorre uma fixação dos conhecimentos científicos a partir da aplicação do discurso didático relativo ao cotidiano vivido e experimentado do aluno. Portanto, podemos admitir que este conflito entre formas de linguagens e símbolos, gera, na mente do aluno, as condições necessárias para que o mesmo chegue a uma a construção de uma aprendizagem real dos conteúdos. Neste processo, o vocabulário e a terminologia cumprem importante papel de facilitadores do aprendizado (BERTOLINI, 2010). Possibilitando, assim, o uso da etnogeomorfologia como recurso didático, valorizador de nomes e conhecimentos dos alunos sobre as formas de relevo circundantes, no ensino do relevo na Educação Básica.

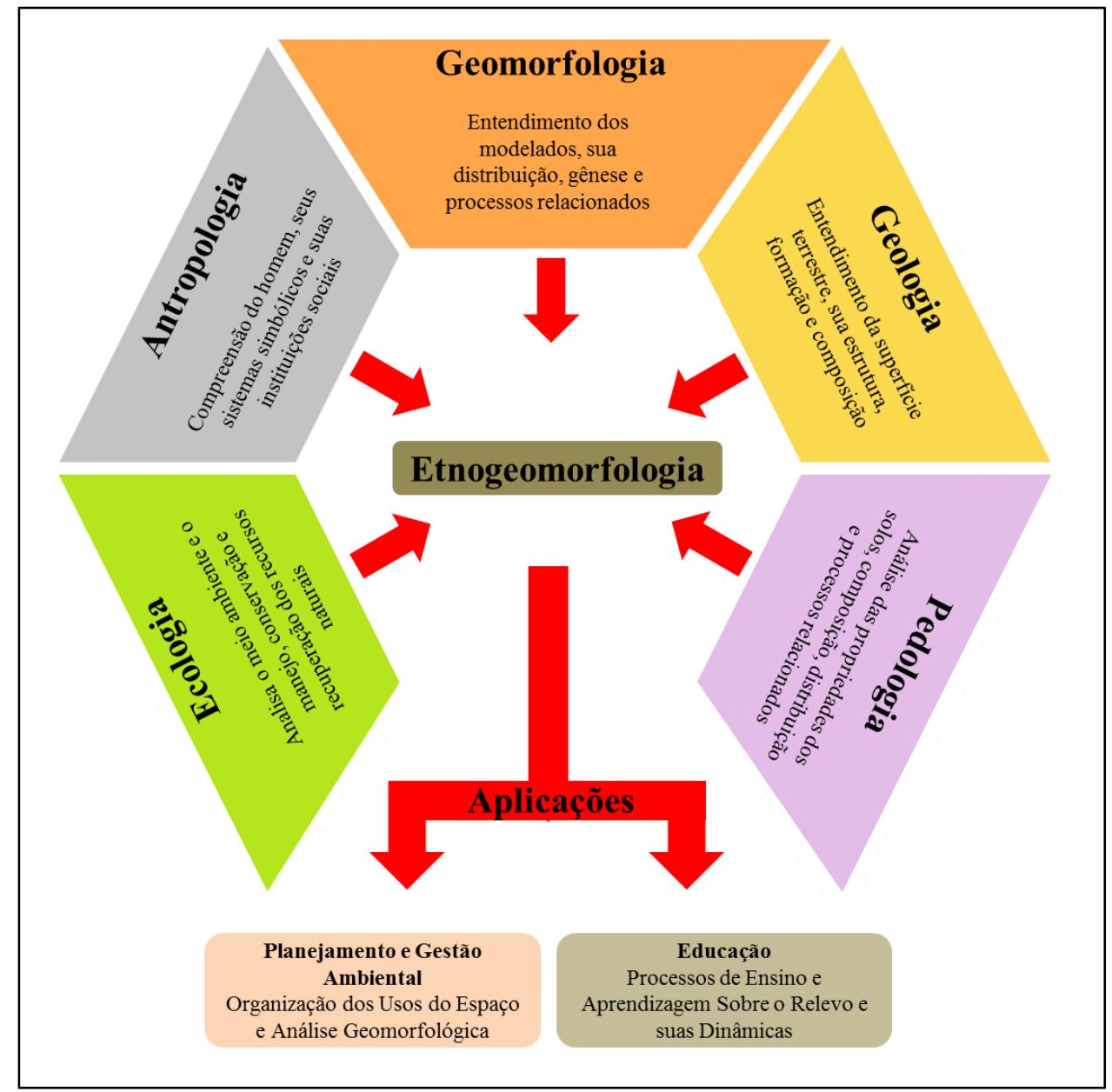

Figura 01 - Contribuições dos diversos campos na formação da Etnogeomorfologia e suas aplicações. Fonte: Elaborado pelos autores, 2019. 
É reconhecido que o estudo do relevo constitui-se importante ferramenta na Educação Ambiental, no planejamento e no manejo de recursos naturais, sabendo que a partir do século XX, grandes transformações sociais fizeram com que estes bens passassem a ser utilizados de forma irracional, o que trouxe um alerta à sociedade sobre a importância e valorização de estudos em Ciências Naturais (GUERRA, 1978). O fato de estes estudos apresentarem relevância social não consiste em uma informação inédita, que mereça ser apresentada detalhadamente neste trabalho. No entanto, é pelo próprio reconhecimento da importância da Geomorfologia à vida humana e à Sociedade que admite-se a necessidade de uma ciência em total conexão com o seres humanos e não alheia a estes sujeitos em algum momento, como muitas vezes se demonstra, no meio educacional brasileiro, onde os elementos naturais das paisagens são apresentados isoladamente, sem suas interrelações entre si e com as sociedades humanas (CASTROGIOVANNI et al., 2003).

Os espaços educacionais podem e devem ser cenários da valorização do saber do outro, da construção conjunta do saber científico, sem com isso, desvalorizar os saberes populares do vivido e experimentado dos estudantes. Nesse contexto de possibilidades e saberes ligados ao "etno", ou mais especificamente a relação entre a Ciência e suas aplicabilidades no reconhecimento e valorização dos conhecimentos tradicionais é que se pensou na presente proposta de discussão sobre a possibilidade de inserção de uma "Etnogeomorfologia" como possibilidade didática, em estreita relação entre a sociedade, o conhecimento científico e o ensino do relevo.

\section{MATERIAIS E MÉTODOS}

A temática pesquisada no presente estudo é bastante recente e necessitou ser organizada com base em uma extensa revisão bibliográfica, abarcando os temas ligados à Etnociência e ao Ensino de Geografia Física, principalmente no tocante ao relevo. Este desafio é empregado toda vez que se busca realizar uma revisão conceitual e propor novas abordagens e discussões em torno de terminologias pouco e/ou muitas vezes não empregadas em determinado ramo científico, bem como, sua transposição didática nos discursos e práticas pedagógicas em sala de aula na Educação Básica. Tendo como pondo de partida a valorização dos saberes populares e bagagem acumuladas pelos alunos ao longo da vida.

A emergência de uma "etnogeomorfologia", em meio ao ensino do relevo, demanda considerações bastante abrangentes, uma vez que essa temática encontra resistências principalmente frente à produção bibliográfica e métodos de aplicabilidade dessa nova conceituação nos estudos sobre o Ensino de Geografia na Educação Básica. Constituindo, a etnogeomorfologia, campo promissor e desafiador a todos aqueles que objetivarem discutir essa abordagem ou "subdivisão" da Geomorfologia, no tocante ao ensino do relevo. Nesse sentido, as metodologias e a epistemologia 
para uma "etnogeomorfologia" e sua aplicação em trabalhos acadêmicos têm sido esboçadas por alguns autores, nos últimos anos. No entanto, nenhum destes trabalhos a apresenta como base a temática do ensino, priorizando descrições feitas em trabalhos de campo, sobre os conhecimentos e terminologias relatadas pelas populações.

Se reconhece, porém, que este tema é muito recente e carece de melhor conceituação para popularizar sua utilização no ensino do relevo. O que pode ser percebido com clareza, no entanto, é que a aproximação do ensino do relevo com uma "etnogeomorfologia" poderia trazer a valorização do conhecimento popular para a sala de aula, sem com isso, desmerecer ou retirar a importância do conhecimento científico no ensino de Geografia.

A sequência metodológica empregada, no presente estudo, priorizou, em primeiro momento, as contribuições teóricas, elencadas ao longo da revisão bibliográfica, como base para a proposição de uma discussão sobre a etnogeomorfologia como possibilidade didática. Para com isso, propor o uso da terminologia e conhecimentos da Etnogeomorfologia como campo de integração de saberes no fazer pedagógico em sala de aula. A sequência dos procedimentos e etapas utilizados ao longo do estudo estão organizados no fluxograma (fig. 02) a seguir:

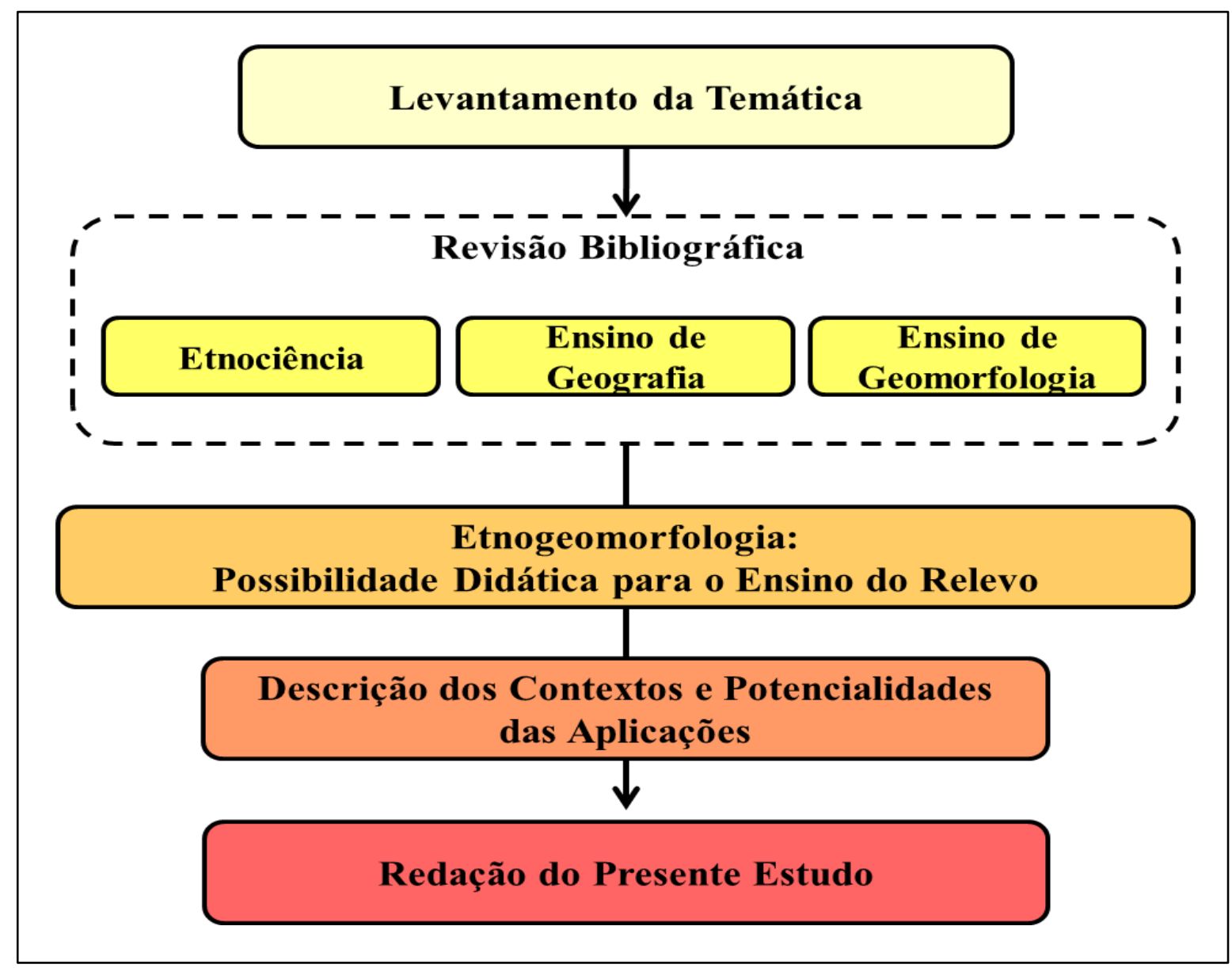

Figura 02 - Sequência metodológica de organização do presente estudo. Fonte: Elaborado pelos autores, 2019. 


\section{RESULTADOS E DISCUSSÕES}

Sendo a Geomorfologia, um ramo da Geografia Física, mantém contato direto com a discussão sobre a sociedade e suas interações espaciais. Sendo essas, influenciadoras da vida dos sujeitos, nesse contexto, os estudos geomorfológicos vem inserindo a população como variável nos sistemas e dinâmicas geomórficas, em uma relação de reciprocidade. Nesse sentido, o etno pode contribuir para a valorização dos saberes populares e sua inserção nos espaços formais de ensino, onde nem sempre são abordados.

O ponto de partida para o presente trabalho constitui a busca por entender a relação entre os estudos do meio físico e a vida dos indivíduos, protagonistas nas relações sociedade-natureza, no entanto, muitas vezes negligenciados ao longo do processo de produção do conhecimento sobre o tema, fazendo com que se estude a natureza pela natureza, de forma descritiva, classificatória e desconectada da realidade vivida (CARVALHO NETA et al., 2014). Aproximar esses dois saberes valorizando ambos e buscando pontos de equilíbrio é que o se propõe no presente estudo.

Dependendo do modo de apropriação do relevo pelo homem, poderão ser desencadeadas consequências positivas ou negativas para os sistemas geomorfológicos, onde a sociedade deve inserir em suas preocupações cotidianas uma reflexão sobre o processo de ocupação das terras e o respeito a dinâmica natural, levando em consideração os potenciais e limitações ambientais. Trazendo à tona a preocupação do ser humano em fixar-se adequadamente num determinado local e desenvolver suas atividades.

A intervenção humana sobre a natureza, remonta ao próprio desenvolvimento da civilização. Nos dias atuais, a relação de identidade que as comunidades desenvolvem com o lugar onde se fixam, tem sido consideravelmente alterada e a importância destas relações, consideravelmente minimizada, em virtude do advento das revoluções econômico/sociais e da globalização, que transformaram as configurações e a dinâmica espacial (LOPES, 2017; ANTUNES ; RIBEIRO, 2018). Essas relações dão origem a espaços diferenciados de ocupação, principalmente ligados a faixas de renda, constituindo áreas de atração populacional, ligadas a uma série de infraestruturas, e outras ligadas a exclusão social. Sendo o relevo, ora um atrativo pela facilidade de ocupação e/ou beleza paisagística, ora dificultador da ocupação, dada a sua morfologia rugosa e de difícil fixação. Nesse segundo exemplo, a ocupação tende a ser realizada não por atrativos formais, mas sim, pela exclusão social, com falta de oportunidades e o não planejamento territorial adequado.

A Ciência e a Educação têm a capacidade de promover um exercício reflexivo sobre as ações humanas no espaço e as Geociências têm a capacidade de fornecer uma ligação entre o homem e o espaço físico no qual habita. Algumas das necessidades humanas que podem ser supridas graças a contribuições das Ciências da Terra são listadas por Cordani (1995), dentre estas 
necessidades estão o monitoramento do Sistema Terra, gerenciamento e fornecimento de recursos minerais e energéticos, conservação e gestão de recursos hídricos e dos solos, além da prevenção e mitigação de desastres naturais.

Fernandes-da-Silva et al. (2018) enfatizam o importante do papel exercido pela Geomorfologia, na gestão ambiental e no planejamento do uso das terras, chamando atenção para a instabilidade dos ambientes onde vivem certas populações mais tradicionais, inclusive sofrendo o descaso do Estado. Algo que vem a ser relevante para a aplicação prática dos estudos “etnogeomorfológicos", uma vez que os ambientes em que vivem estas populações envolvem produtividade e também a própria subsistência delas, em relação direta com o relevo. A exemplo dos povos caiçaras, coletores de mariscos, nos alagados, coletores de castanhas e outros derivados florestais, produtores arrozeiros, criadores de alevinos e crustáceos, dentre tantos outros. Atividades essas intimamente ligadas com a configuração do relevo circundante, tanto em meso quanto em micro escala.

A transposição, ou o intermédio entre o conhecimento científico específico de um determinado campo para determinado setor da sociedade, dar-se-á por meio de uma atividade conectiva, reconhecida por Dominguini (2008), como sendo a atividade didática, o ensino. Esta ligação se fundamenta a partir da apropriação pelas novas gerações de conhecimentos, valores e hábitos de gerações anteriores, que são transmitidas dentro do contexto do conhecimento escolar. O grande desafio, no tocante ao ensino do relevo, constitui trazer para o ambiente escolar a valorização dos saberes culturais sobre o relevo, tanto aqueles ligados ao nome quanto aos processos morfodinâmicos.

A simbiose entre os saberes empíricos e o conhecimento formal pode fazer com que o ensino sobre o relevo seja mais participativo e inclusivo, onde a transposição didática possibilita correlações entre o mundo vivido e experimentado dos indivíduos e o saber científico. Sem a desvalorização da ciência e com a inclusão do saber popular nos ambientes formais da Educação. Daí a proposta da etnogeomorfologia como ferramenta didática no ensino do relevo na Educação Básica, com fazeres e práticas mais inclusivos. Em contra partida, atualmente, pode-se perceber abordagens e práticas na atividade docente que parecem manifestar um esquecimento, e às vezes até mesmo certo menosprezo à importância social dos saberes populares na Escola. Uma das práticas que denotam esta descrença é a não valorização dos conhecimentos empíricos que além de conectar o aluno ao conhecimento científico, podem facilitar a aprendizagem sobre os conteúdos trabalhados.

Ao se inserir a Etnogeomorfologia, no ensino do relevo, a Escola ganha, desta maneira, o papel de instituição inclusiva, facilitando as ações e relações humanas além de promover as mudanças positivas necessárias para o desenvolvimento de uma sociedade harmônica e ambientalmente consciente. Isto só foi possível graças a novas contribuições teóricas no cenário pedagógico, o que se 
deu principalmente a partir da segunda metade do século XX (LIBÂNEO, 2005). É nesse cenário que se propõe o etno nos fazeres pedagógicos em Geografia Física, no que se refere ao ensino do relevo e suas interlocuções com outros saberes geográficos. Neste sentido, pensando em abordagens e práticas didáticas pedagógicas efetivas que valorizem a transposição de conhecimentos científicos, a Etnogeomorfologia surge como ferramenta intermediadora entre os saberes técnicos e as constatações empíricas populares, mostrando-se como um instrumento didático efetivo na transposição de conhecimentos complexos inerentes a compreensão da dinâmica geomorfológica processual e histórica.

\subsection{A valorização dos conhecimentos populares na aprendizagem em Geomorfologia}

Os conhecimentos populares, empíricos, são uma ferramenta cognitiva muito importante, já que estão ligadas intimamente ao mundo vivido do aluno. Sua valorização deve ser estimulada á medida que podem facilitar sua percepção de familiaridade com os conhecimentos curriculares científicos, criando assim um vínculo entre a realidade do aluno e o que lhe é apresentado cientificamente em sala de aula. O contato entre estas duas formas de comunicação é, às vezes, conflituoso, fazendo com que haja uma ressignificação de ideias, o que proporciona, finalmente, uma maior reflexão e internalização de novos conceitos construídos. (COSTA, 2008).

Os conteúdos relacionados à Geomorfologia requerem certa capacidade de abstração nem sempre apresentada pelos alunos. É o que observaram Torres ; Santana (2009), chamando atenção também para a necessidade da utilização de meios didáticos diferenciados para esta área de estudo. Ao mesmo tempo, o relevo está diretamente presente no cotidiano das sociedades, por isso, a possibilidade de uma "etnogeomorfologia", como propõe o presente estudo. O etno configura uma possibilidade de equilíbrio e mediação de conhecimentos na construção de novos saberes, nesse caso específico, as formas de relevo e processos morfodinâmicos. Essa mediação deve se dar pela valorização do conhecimento prévio dos alunos, quando da estimulação para que os mesmos apresentem os saberes trazidos de uma bagagem histórica e cultural dos grupos sociais.

A Geomorfologia apesar de possuir um conjunto diversificado de terminologias para as morfologias e um vasto aparato técnico, ao ser apresentada de maneira muito formal, pode causar certa dificuldade na construção do conhecimento pelos alunos (ASCENÇÃO ; VALADÃO, 2017). A variedade de nomes para definir formas semelhantes leva a um cenário em que a há quantidade excessiva de definições e conceitos a serem trabalhados em sala de aula. Além disso, essas terminologias estão muito ligadas a bagagem teórica e convívio social dos estudiosos que a propõem, levando a muito desconhecimento de termos ou dificuldade de memorização em um país de dimensões geográficas e diversidades socioculturais como o Brasil. 
A valorização dos saberes individuais e coletivos dos alunos, quando estimulados a expressá-los em sala de aula, como primeira etapa das aulas sobre o relevo, na Educação Básica, pode fazer com que o processo de ensino aprendizagem fique mais divertido, dinâmico e atrativo. Com isso, o conhecimento científico se aproximaria do mundo real, vivido e experimentado pelos alunos, aproveitando sua própria experiência com o lugar em que vive (PEREIRA ; SILVA, 2012). Esse constitui desafio proposto pelo presente estudo, inserir os alunos e sua bagagem de conhecimento cultural no processo educativo. Para isso, faz-se necessário que esses indivíduos se sintam confortáveis e estimulados a expressar seus saberes, dando significado as novas competências e habilidades desenvolvidas.

O papel da Educação Formal, numa perspectiva de construção de saberes, é o de munir os alunos das ferramentas necessárias as análises geográficas (CASTELLAR ; JULIASZ, 2017). Nesse sentido, o processo de ensino aprendizagem constitui um letramento geográfico (Fig.03), ou seja, a aprendizagem de uma série de conceitos, categorias e metodologias de análise, em um direcionamento a partir da etnogeomorfologia, possibilita as leituras das interações e correlações espaciais do relevo. A inserção dos saberes populares nos cenários educacionais constitui uma possibilidade concreta de utilização da categoria de lugar, um importante instrumento nos estudos em Geografia, dados os apegos e pertencimentos espaciais envolvidos.

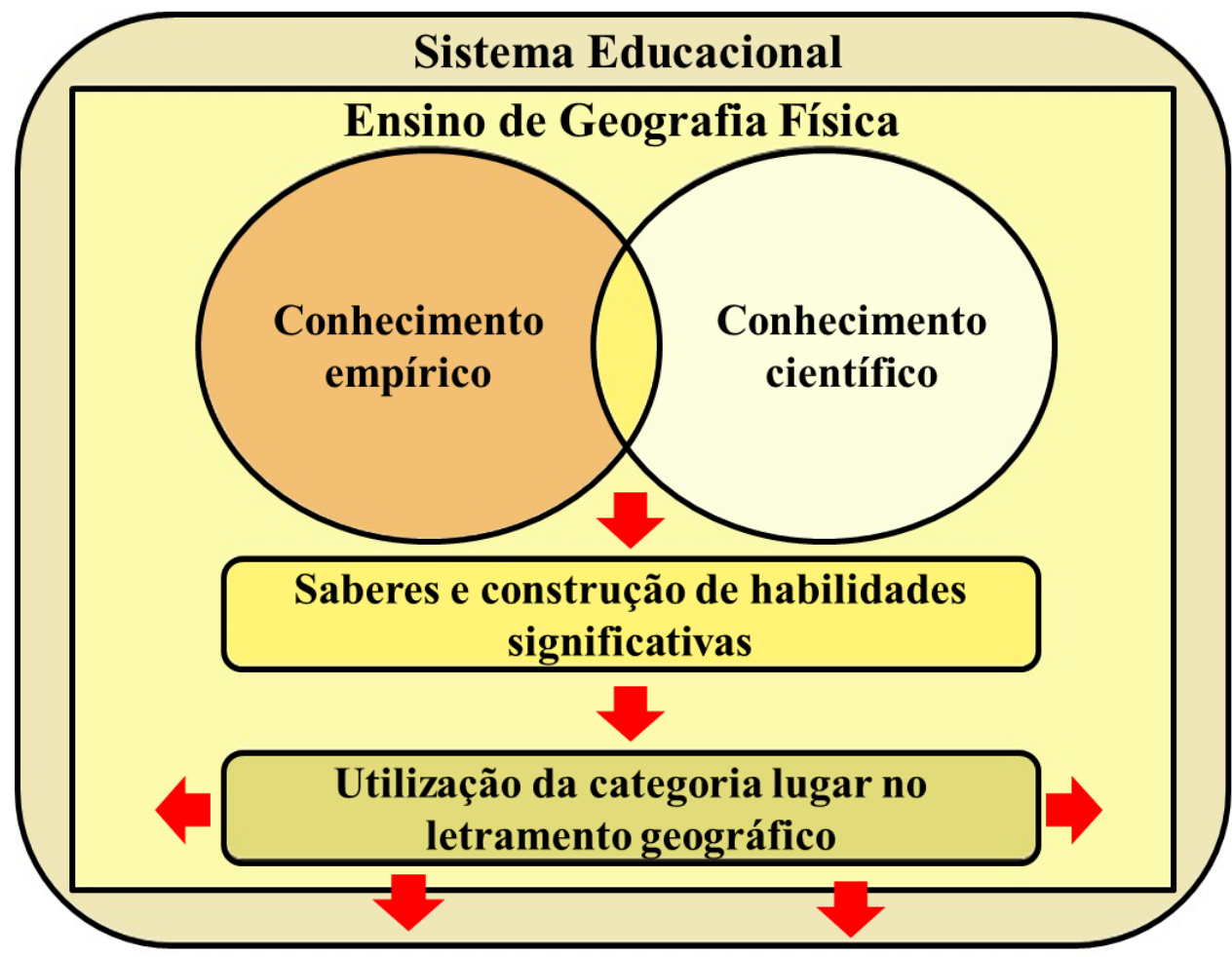

Figura 03 - Processo de ensino aprendizagem numa perspectiva significativa na Educação Básica.

Fonte: Elaborado pelos autores, 2019. 
A linguagem conceitual utilizada nas aulas de Geografia Física, não só na Geomorfologia, assim como nas Ciências Naturais, assume uma forma técnica que, por muitas vezes, é desconectada da realidade cotidiana da sala de aula, sobretudo na Educação Básica, sem qualquer diálogo com a realidade do mundo vivido pelos alunos. As origens dessa ausência de articulação entre o conhecimento formal e os saberes populares, no processo educacional, remonta a formação acadêmica dos professores de Geografia. Assim como os saberes empíricos dos alunos não dialogam com os conhecimentos científicos na Escola, muitas vezes o mesmo fenômeno ocorria nas salas de aula do Ensino Superior, quando da formação dos professores em atuação nessas salas de aula. Constituindo um ciclo vicioso de dificuldades de articulação na transposição didática, quando o conhecimento científico deve ser apresentado de forma clara, compreensível, diversa e o mais acessível possível ao público ouvinte.

A proposição da utilização da etnogeomorfologia, em sala de aula, na Educação Básica, esbarra no desafio, muitas vezes, da falta de articulação entre a formação dos professores e a realidade educacional nas Escolas. Faz-se necessário aproximar essas duas formações, a do professor e a dos alunos, em um processo de trocas e reciprocidade. Tais interações devem vir de ações de extensão e oficinas didáticas que envolvam as comunidades acadêmicas e escolares, sem hierarquias, preconceitos ou arrogâncias. Um professor bem formado, munido de experiências, saberes e bagagem teórica, tem plena capacidade de dinamizar suas aulas, tornando os processos educacionais divertidos, propositivos, inclusivos e diversos, em contraposição a atividades mecânicas e produtivistas tão cotidianamente encontras atualmente nas aulas de Geografia.

Nas aulas sobre o relevo, as explicações sobre determinados processos e morfologias, em geral, se tornam ineficientes à aprendizagem, levando inclusive os estudantes ao desinteresse sobre o tema. A maior parte dos termos científicos possui uma conotação apenas diferente de termos usados no dia a dia desses alunos, os processos e formas, no entanto, os mesmos conhecem. Não sendo isto, muitas vezes, levado em consideração ou valorizado em sala de aula. A não aproximação do conhecimento científico com o mundo que rodeia o aluno, com o uso exagerado de termos científicos formais e exemplos distantes, torna-se claramente um obstáculo à aprendizagem. A conceituação, além de não ser em si uma ferramenta de aprendizagem propriamente dita, também não deve ser usada de forma desconexa e sem a necessária construção lógica de ideias que possibilita ao aluno uma definição própria do tema. Para que isto ocorra, o professor deve estimular a expressão e uso dos conhecimentos prévios de seus alunos (BERTOLINI, 2010). Daí, a necessidade de se repensar as práticas e fazeres pedagógicos em Geomorfologia, aproximando o conhecimento científico do mundo real, vivido e experimentado.

Uma educação mecânica transmite (literalmente) conteúdos técnicos, reproduzidos, partindo da ideia de que o aluno não tem a mínima noção do que está a ser estudado. Tal modelo é unilateral 
e sem interação alguma entre os elementos e participantes do processo de ensino aprendizagem (KAERCHER, 2010). O aluno, porém, consegue assimilar os conteúdos apenas interiormente, dando significados a alguma ideia que já é presente em sua estrutura cognitiva. Por isso, deve ser estimulado a expressar seus saberes prévios no processo de construção dos novos saberes e habilidades ao longo das aulas.

No mundo atual, complexo e diverso, cheio de possibilidades e ferramentas de comunicação, cabe à Ciência e ao Educador facilitar a ocorrência da aprendizagem, tornando a educação um processo divertido e estimulante, valorizando aquilo que o aluno já tem de experiência, na intenção de posteriormente reorganizar e introduzir novas abordagens e terminologias por meio da geração de conflitos (criados com a apresentação de situações-problema) ou acrescentar novas concepções sobre o tema estudado (SCHNETZLER, 1992; MORTIMER, 2016). Nesse sentido, deve-se levar em conta as vivencias dos alunos, o que implica em apreender seus conhecimentos prévios e sua experiência em relação ao conteúdo trabalhado, podendo coexistir com outras ações, como, por exemplo, as atividades de observação (CAVALCANTI, 2013).

A relação entre os conhecimentos científicos e populares e a ligação dos mesmos com a Educação e com a Sociedade (fig. 04), constitui um fator imprescindível para que se tenha uma estruturação de ideias que merecem ser reverberadas, propiciando uma aprendizagem facilitada sobre temas objetivamente aplicáveis em benefício das comunidades circundantes (SOUZA, 2018). Esta relação, assim como a inserção da Geomorfologia e uma abordagem popular, pode estimular o desenvolvimento de novos fazeres e práticas no ensino do relevo.

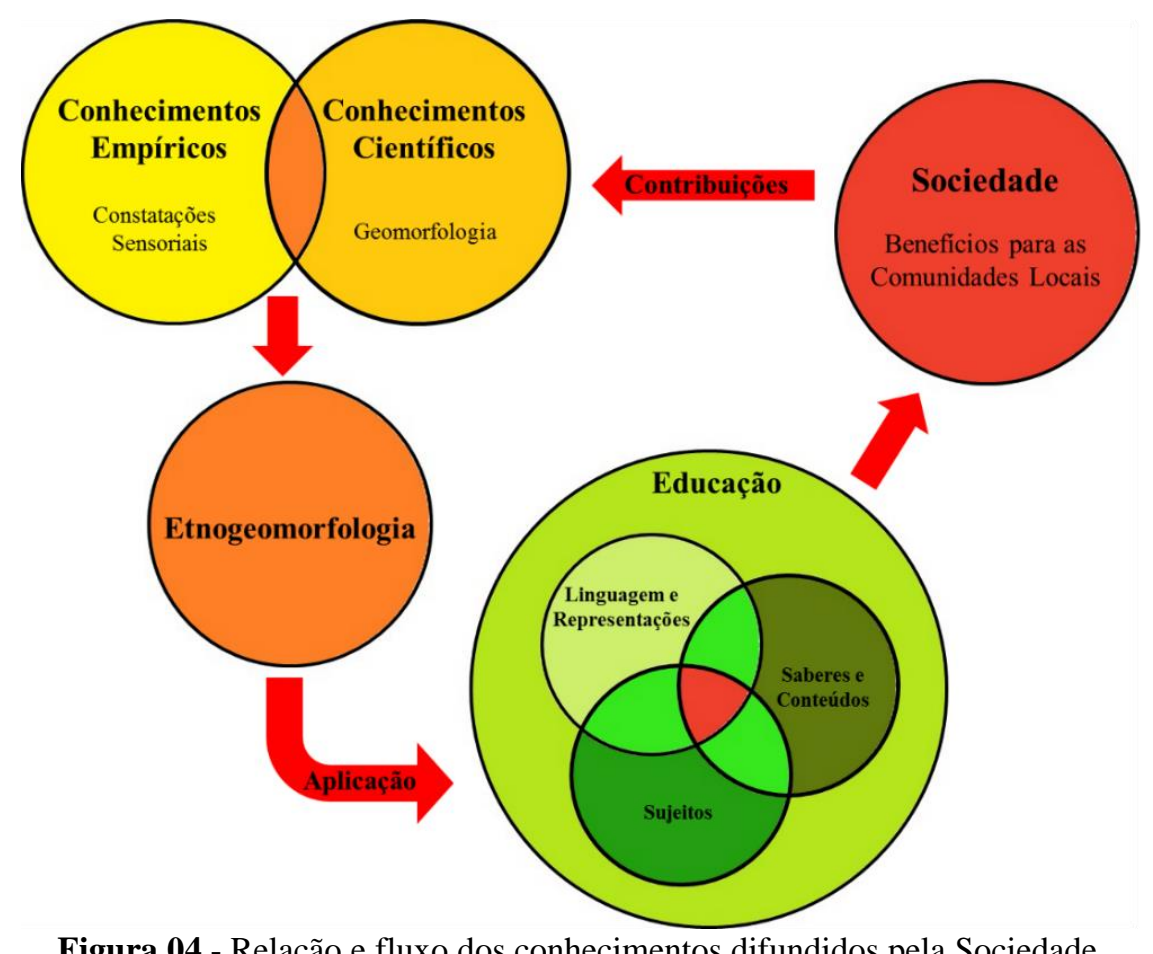

Figura 04 - Relação e fluxo dos conhecimentos difundidos pela Sociedade.

Fonte: Elaborado pelos autores, 2019. 


\subsection{Aplicações da Etnogeomorfologia em sala de aula}

Após discutir sobre a importância de se utilizar a etnogeomorfologia como proposta didática, devemos tratar de como estes conhecimentos seriam colocados em prática na escola, apresentando proposições para atividades e fazeres pedagógicos. Vale salientar que a proposta deste trabalho não é apresentar uma metodologia bem estruturada de aplicação da etnogeomorfologia em sala de aula, mas sim uma discussão sobre a aplicação da etnogeomorfologia como possibilidade didática. As especificidades e fazeres, dada a diversidade de paisagens, grupos sociais e culturais, devem ser pensadas de modo a atender as características dos locais de aplicação. Nesse sentido, as metodologias de utilização do etno no ensino do relevo deverão ser trabalhadas numa perspectiva de pertencimento e apropriação, muito íntima da categoria de lugar na Geografia.

A Geografia como disciplina curricular, permite aos alunos os primeiros processos de reconhecimento das paisagens, sua dinâmica e constituição, deixando de lado a mera visualização descritiva e conformista da paisagem, passando a uma compreensão integrada de seus aspectos tratando as paisagens como elementos dinâmicos, onde o componente principal é o relevo, uma vez que representa o substrato da paisagem, controlando os fluxos horizontais de energia e matéria, além de dar sustentação as atividades biológicas e antropogênicas (CAVALCANTI ; CORRÊA, 2017). Construindo em certa parte noções primárias de sua dinâmica integrada do meio natural, mesmo que de forma mais simples e fácil apreensão.

A Geomorfologia, disciplina acadêmica presente na formação dos professores de Geografia, historicamente está muito ligada a categoria de paisagem. Por esse motivo trabalha com linguagens teóricas e visuais, noções espaço temporais e estimulo a abstração, como ferramentas de construção dos saberes sobre os conjuntos morfológicos, processos e sistemas de funcionamento das paisagens. Essas ferramentas e métodos são importantes na formação docente, no entanto, nem sempre são efetivas na transposição didática na Escola. Daí a necessidade de valorização do mundo vivido e experimentado dos alunos como ponto de partida para a construção de saberes sobre o relevo. Esses indivíduos, ao chegarem a sala de aula, já conhecem o relevo, seus desníveis e formas, o que lhes falta é a formalização desses saberes numa perspectiva científica. Nesse momento é que se dá o processo de letramento geográfico, com inserção de conceitos, metodologias e classificações que guiarão a interpretação e descrição do relevo, agora, numa estruturação formal.

Ao se realizar a transposição didática da Geomorfologia para o ensino do relevo na Escola, faz-se necessário que o conceito de relevo não seja, para o aluno, apenas aquilo que é perceptível na paisagem. Seu entendimento exige também a abstração, uma vez que é preciso entender os processos atuais e transformações ao longo do tempo que possibilitaram a estruturação atual do relevo. Sendo imprescindível, em primeiro lugar, que o aluno reconheça os elementos da paisagem em sua 
linguagem e saiba transpor, posteriormente, para a linguagem científica (BERTOLINI, 2010). É nesse momento que a etnogeomorfologia aparece como possibilidade didática, uma vez que valoriza o conhecimento empírico dos alunos e estimula o seu uso em sala de aula no processo de letramento geográfico. Para isso, o Professor de Geografia deve ter cautela ao utilizar a paisagem como forma de trazer significado aos alunos dos conceitos científicos relacionados ao relevo, uma vez que a temática exige certa subjetividade e complexidade. Um caminho possível, no sentido de diminuir o impacto da formalização dos saberes, seria a inserção de atividades e instrumentos lúdicos pedagógicos em sala de aula.

Em sala de aula, numa perspectiva de utilização da etnogeomorfologia, o professor deve estimular os alunos a apresentarem as características dos relevos aos quais estão inseridas suas atividades cotidianas. Para isso, deverá organizar um espaço de diálogo onde esses indivíduos se sintam valorizados e expressem os conhecimentos que trazem de sua formação pessoal, social e cultural. Listadas as formas de relevo, já conhecidas, cabe ao professor iniciar o processo de letramento, apresentando os conjuntos locais, regionais e globais em que essas morfologias estão inseridas. Além de inferências sobre outras temáticas que tem relação direta com o processo de estruturação e esculturação do relvo, a exemplo das rochas, condições climáticas, solos, vegetação, hidrografia e atividades antropogênicas.

Para as atividades que exigem mais abstração, faz-se necessário a utilização de ferramentas como fotografias, projeções, desenhos interativos e recursos visuais em geral, tentando construir noções como profundidade, proximidade, volume e distância. A visualização em 3D, ajuda no processo de abstração e percepção das diversas morfologias, sobretudo, aquelas que não fazem parte do cotidiano dos alunos. Desse modo, sempre que possível no ambiente escolar, é imprescindível o uso das tecnologias educacionais (TICs), auxiliando na percepção visual e abstração nos fazeres pedagógicos.

Uma das práticas que tem se tornado efetivas na transposição de conhecimentos geomorfológicos científicos, através de saberes prévios dos alunos, são estruturas e blocos tridimensionais explicativos, que se utilizem de ferramentas de abstração e profundidade na representação do relevo (Fig. 05). Essas novas ferramentas, mais tecnológicas, vem a substituir e/ou complementar o já tão consagrado uso de maquetes do relevo. Ao se utilizar essas ferramentas podese seguir dois caminhos metodológicos: 1) apresentar a mesma representação com as nomenclaturas populares e depois sobrepor a classificação científica das formas; 2) na mesma representação inserir as duas nomenclaturas, dando ao aluno a possibilidade de correlação imediata. Ambos os caminhos podem trazer resultados positivos, sendo a escolha, realizada com base na vivência cotidiana e formas de apreensão percebidas pelo professor ao aplicar novas metodologias em sala de aula. 
As representações, utilizadas em sala de aula, devem demonstrar o relevo para além dos compartimentos altimétricos, fornecendo informações sobre a composição e estrutura, além dos aspectos morfológicos distintos no contexto local, permitindo a discussão de forma simplificada e explicativa, aproveitando-se das definições, conhecimentos e nomenclaturas locais. Isso pode contribuir para que os alunos reconheçam as formas para além das corriqueiras definições mecanicistas sobre o relevo, como as apresentadas, cotidianamente, no ensino fundamental e médio, onde apresenta-se uma fotografia, dar-se um nome, e ao final, espera-se que aqueles indivíduos consigam entender e descrever as formas do relevo.

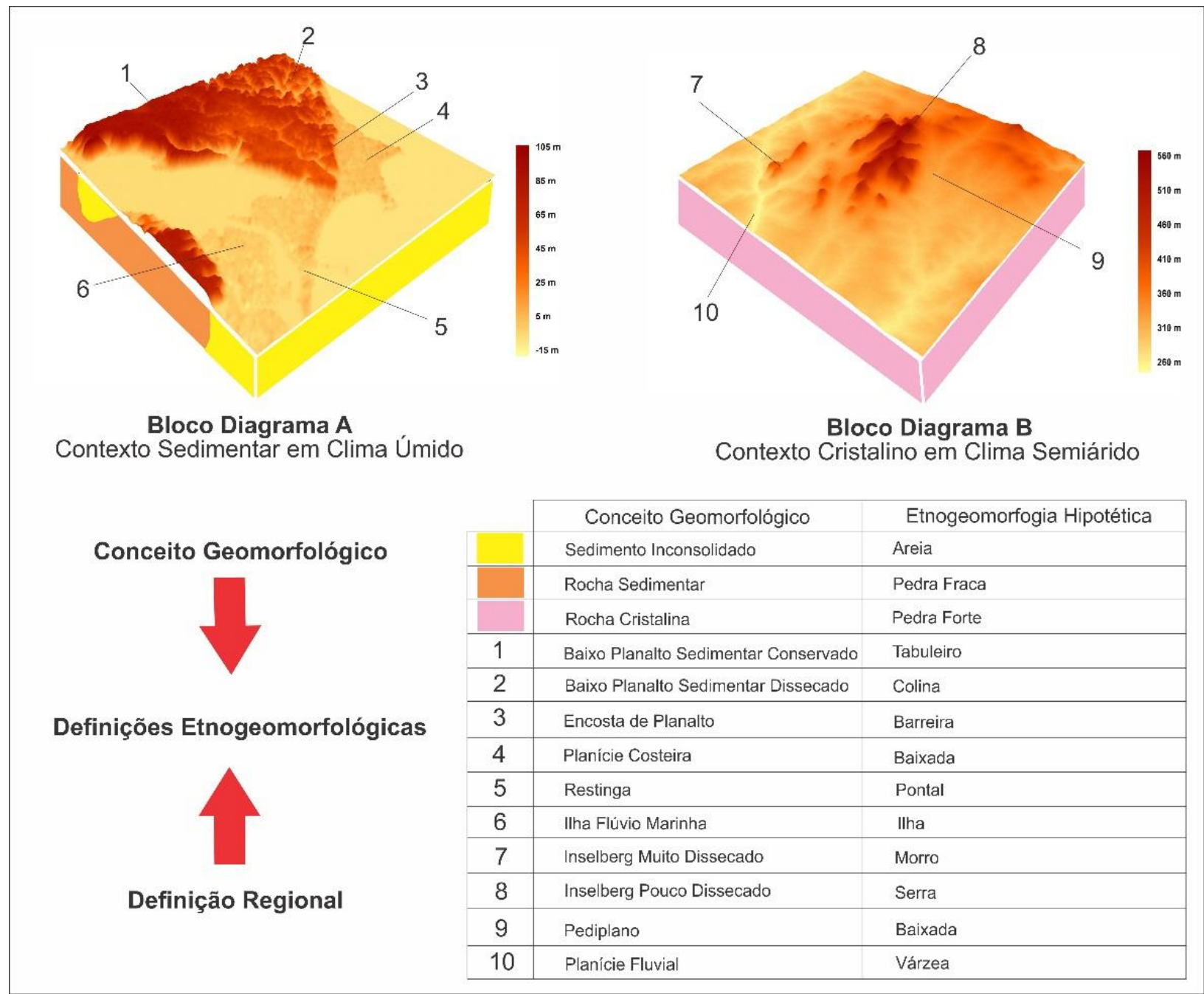

Figura 05 - Blocos diagramas comparativos das noções geomorfológicas e etnogeomorfológicas com exemplos de formas de relevo e nomenclaturas populares.

Fonte: Elaborado pelos autores, 2019.

Outro agravante é que a maior parte das representações do relevo, presentes nos livros didáticos, não dialogam com o cotidiano dos alunos (CASTELLAR ; JULIASZ, 2017). Além de uma apresentação mecânica, impositiva e pouco dinâmica das classificações geomorfológicas, os alunos 
não reconhecem aquelas formas ali apresentadas, tão pouco, tendem a construir um sentimento de pertencimento, o que leva ao desinteresse sobre o que se está trabalhando. Essa dinâmica, em um momento de uso intenso de tecnologias e formas rápidas de comunicação, tendem a favorecer a não participação nas aulas, levando ao cenário tão cotidiano atualmente, onde se percebe os alunos utilizando celulares em sala de aula, sem se envolver com o que está sendo discutido e/ou apresentado (TIMBANE et al., 2015). Nesse contexto, a etnogeomorfologia vem a contribuir com a construção dos pertencimentos e representatividades por parte dos alunos, visando trazer de volta a atenção e participação, tão necessários ao se estudar o relevo.

Além do conteúdo disciplinar específico, ligado ao ensino do relevo, exemplos de fenômenos, observados cotidianamente, devem ser utilizados no dia a dia da sala de aula. Eventos meteorológicos intensos, cheias, processos erosivos acelerados, abrasão marinha, ressacas e tantos outros eventos que ocorrem nas cidades e zonas rurais são amplamente divulgados nos meios de comunicação. A televisão, já consolida, e a internet que tem adentrado os lares, estão cheios de notícias sobre os mesmos, sendo caminho promissor a sua utilização ao longo das aulas. Quando algo corriqueiro encontra espaço na sala de aula, os saberes acumulados tendem a encontrar eco na discussão dos conteúdos. Estimular a pesquisa extra sala em meios de comunicação pode fazer com que os alunos se sintam estimulados a estudar os conteúdos.

O papel do professor na sala aula deve ser o de mediador entre o conhecimento científico e o saber popular, promovendo a transposição didática de forma simples, estimulante e divertida. Para isso, pode-se fazer uso de imagens, jornais, revistas, TICs, gincanas, experimentos, exposições, festivais, trabalhos de campo, visitas técnicas e tantas outras possibilidades didático-pedagógicas. De preferência, utilizando materiais de fácil aquisição e que possam ser providenciados pelos próprios alunos, promovendo a sua participação em todas as etapas do processo. Em meio a isso, a etnogeomorfologia, surge como uma linguagem simbólica e está relacionada à percepção humana, não importando que tipo de imagem, ou que tipo de "mundo", real ou virtual, está sendo explorado.

Ao professor, cabe intermediar o desenvolvimento um olhar geográfico nos alunos, o letramento geográfico, se utilizando dos recursos e tempo disponíveis, permitindo aos mesmos aprender a "construir explicações para a realidade vista empiricamente, vivida cotidianamente por eles, como sendo uma realidade com dimensão espacial, e, com isso, muni-los de instrumentos simbólicos para sua relação (mediada) com essa mesma realidade” (CAVALCANTI, 2017, p. 108).

Ao se apresentar uma proposta metodológica, sem um conjunto de procedimentos a serem seguidos, embasada numa discussão conceitual e proposições alinhadas com as ideias construtivistas e da educação significativa, o que se pretende é chamar a atenção para o tema e mais ainda para a possibilidade de desenvolvimento de novos fazes e práticas no universo educacional, especialmente, no tocante ao ensino do relevo. Nunca foi uma premissa propor etapas, formas ou conjuntos de 
procedimentos rígidos e estruturados numa sistemática fechada, mecanicista. O “chão da escola" e o cotidiano da sala de aula são muito complexos e cheios de particularidades para que se proponha assertivas sobre os fazeres pedagógicos. Como o presente estudo se estruturou em uma discussão e proposição de fazeres, sem que houvesse tempo para testes e avaliações de aplicabilidade, optou-se por discutir propostas amplas e direcionadas a reflexão sobre as possibilidades da etnogeomorfologia no ensino do relevo.

Ao afinal, o que se propõe é que todas as atividades didáticas estejam totalmente conectadas a realidade do mundo conhecido do aluno. O que se deve fazer, longe de abdicar da linguagem científica e conceitual da Geomorfologia, é aproximar este tipo de conhecimento a uma linguagem que esteja presente no "sistema de crenças" e forma de ver o mundo do aluno, numa perspectiva de aplicação efetiva da categoria de lugar. O etnoconhecimento compreende uma contextualização, um meio norteador didático para ser usado em determinado momento e cenário (CARNEIRO, 2009).

\section{CONSIDERAÇÕES FINAIS}

O presente estudo propôs a idealização de uma etnogeomorfologia como possibilidade, no âmbito das atividades educativas escolares ligadas ao ensino do relevo, para uma aproximação dos conteúdos ligados à Geomorfologia e apresentados em sala, de maneira muito formal, à realidade do mundo cotidiano dos alunos. Propondo o rompimento com técnicas tradicionais, mecanicistas, de abordagem do relevo na Educação Básica. Sugerindo uma reflexão sobre fazeres que estimulem a inserção de conhecimentos empíricos, em um espaço de mediação com os conhecimentos científicos em sala de aula.

Defendeu-se a etnogeomorfologia como uma nova possibilidade no ensino do relevo, em um ambiente de reflexão e discussão conceitual, sem com isso, apresentar atividades efetivas de aplicação e verificação in locu das ações propostas. A efetivação de ações e fazeres, constitui etapa posterior ao momento apresentado ao longo do presente estudo, constituindo ação necessária para a verificação e avaliação, concreta e efetiva, das propostas aqui apresentadas.

Espera-se com esse estudo, estimular a reflexão e auxiliar a ação pedagógica de profissionais do ensino da área de Geografia na Educação Básica, com especial foco a Geomorfologia, a qual chega à sala de aula, estruturada no ensino do relevo. As propostas e discussões aqui apresentadas foram formuladas com bases nas leituras e revisões conceituais realizadas ao longo do presente estudo, sem, contudo, se preocupar em realizar críticas mais aprofundadas sobre as vivências cotidianas em sala de aula. Já que não se trata de um estudo aplicado, com cenário, objeto e área geográfica específica. 


\section{REFERÊNCIAS}

ANTUNES, M. R. V.; RIBEIRO, S. C. Etnogeomorfologia sertaneja: saberes tradicionais da agricultura familiar sobre os processos morfoesculturadores da paisagem e o seu uso e manejo do solo no Município de Jardim-CE. Revista de Geografia, Recife, v. 35, n. 4, p. 55-67, 2018.

ASCENÇÃO, V. O. R.; VALADÃO, R. C. As abordagens do relevo e suas dinâmicas por professores do ensino fundamental: o conhecimento do conteúdo. Boletim Paulista de Geografia, São Paulo, n. 90, p. 167-178, 2017.

BERTOLINI, W. Z. O ensino do relevo: Noções e propostas para uma didática da geomorfologia. 2008.110 f. Dissertação (Mestrado em Geografia e Análise Ambiental) - Instituto de Geociências, Universidade Federal de Minas Gerais, Belo Horizonte, 2010.

CAMPOS, M. D. Etnociência ou etnografia de saberes, técnicas e práticas? In: AMOROZO, M. C. M.; MING, L. C.; SILVA. S. M. P. (Org.). Métodos de coleta e análise de dados em etnobiologia, etnoecologia e disciplinas correlatas. Rio Claro: UNESP/CNPQ, 2002. p.47-91.

CARNEIRO, M. A. B. A transposição didática e os conteúdos de meio ambiente e educação ambiental em áreas de manguezais na $4^{a}$ série do ensino fundamental. 2009. 183 f. Dissertação (Mestrado em Ensino das Ciências) - Universidade Federal Rural de Pernambuco, Recife, 2009.

CARVALHO NETA, M. L.; RIBEIRO, S. C.; MARÇAL, M. S.; LIMA, G. G. Mapeamento etnogeomorfológico do Distrito de Arajara, Barbalha/CE. Revista Geonorte, Manaus, v. 4, p. 208$212,2014$.

CASTELLAR, S. M. V. Educação geográfica: a psicogenética e o conhecimento escolar. Cad. Cedes, Campinas, v. 25, n. 66, p. 209-225, 2005.

CASTELLAR, S. M. V.; JULIASZ, P. C. S. Educação Geográfica e Pensamento Espacial: conceitos e representações. Acta Geográfica, Caracaraí, Edição Especial: Ensino de Geografia, n. 1, p. 160$178,2017$.

CASTrogiOVAnNi, A. C.; CALlAi, H. C.; SCHÄFFER, N. O. KAERCHER, N. A Geografia em Sala de Aula: práticas e reflexões. 4. ed. Porto Alegre: Editora da UFRGS. 2003. 200p.

CAVALCANTI, L. S. Geografia, escola e construção de conhecimentos. 2. ed. Campinas: Papirus, 2013. 192p.

CAVALCANTI, L. S. Trabalho do professor de Geografia e tensões entre demandas da formação e do cotidiano escolar. In: ASCENÇÃO, V. O. R.; VALADÃO, R. C.; GAUDIO, R. S. D.; SOUZA, C. J. O. (ORGs.). Conhecimentos de Geografia: percursos de formação docente e práticas na educação básica. Belo Horizonte: IGC, 2017. cap. 5, p. 100-123.

CAVALCANTI, L. C. S.; CORRÊA, A. C. B. Geossistemas e geografia no Brasil. Revista Brasileira de Geografia, Rio de Janeiro, v. 61, n. 2, p. 3-33, 2017.

CORDANI, U. G. As Ciências da Terra e a Mundialização das Sociedades. Estudos Avançados, São Paulo, v.9, n. 25, p. 13-27, 1995. 
COSTA, R. G. A. Os saberes populares da Etnociência no ensino das ciências no ensino das ciências naturais: Uma proposta didática para aprendizagem significativa. Revista Didática Sistêmica, Rio Grande, v. 8, p. 162-172, 2008.

DIEGUES, A. C. Saberes tradicionais e biodiversidade no Brasil. 1. ed, Brasília/São Paulo: Ministério do Meio Ambiente/USP, 2001. 189p.

DOMINGUINI, L. A transposição didática como intermediadora entre o conhecimento científico e o conhecimento escolar. Revista Eletrônica de Ciências da Educação, Campo Largo, v. 7, n. 2, p. $1-16,2008$.

FERNANDES-DA-SILVA, ROBERTA K.; LOPES, V. M.; GIRÃO, O. Avaliação preliminar dos conhecimentos etnoclimático e etnogeomorfológico de pescadores do litoral do Município de Goiana - estado de Pernambuco / Brasil. Revista Geografica de America Central, Heredia, v. 1, p. 301$328,2018$.

GUERRA, A. J. T. Considerações a respeito da importância da geomorfologia no manejo ambiental. Boletim Geográfico, Rio de Janeiro, v. 36, n. 258/259, p. 60-67, 1978.

KAERCHER, N. A. Geografia em sala de aula: práticas e reflexões. 2. ed. Porto Alegre: Editora da UFRGS, 2010. 210p

LIBÂNEO, J. C. As teorias pedagógicas modernas revisitadas pelo debate contemporâneo na Educação. In: LIBÂNEO, J. C.; SANTOS, A. (Org.). Educação na era do conhecimento em rede e transdisciplinaridade. Campinas: Alínea, 2005. p. 19-62.

LOPES, V. M. Etnogeomorfologia costeira e estuarina em comunidades de pescadores artesanais no litoral de Goiana, Pernambuco. 2017. 147 f. Dissertação (Mestrado em Geografia) Departamento de Geografia, Universidade Federal de Pernambuco, Recife, 2017.

LOPES, V. M.; RIBEIRO, S. C. Etnogeomorfologia e paisagem. Revista de Geociências do Nordeste, Caicó, v. 2, n. especial, p. 212-220, 2016.

MAIA, D. S. A Geografia e o estudo dos costumes e das tradições. Terra Livre, São Pulo, v. 1, n. 16, p. 71-98, 2015.

MORENO, G. A. M.; DAZA, C. G. La etnografía en el ámbito educativo: una alternativa metodológica de investigación al servicio docente. Educación y desarrollo social, Bogotá, v. 9, n. 2, p. 192-205, 2015.

MORTIMER, E. F. Construtivismo, mudança conceitual e ensino de ciências: para onde vamos?. Investigações em ensino de ciências, Porto Alegre, v. 1, n. 1, p. 20-39, 2016.

PARADISE, R. Etnografía: ¿técnicas o perspectiva epistemológica? In: RUEDA, M.; DELGADO, G.; JACOBO, Z. La Etnografía en Educación: Panorama, Prácticas y Problemas. Cidad México: Universidad Nacional Autónoma de México, 1994. p.73-81.

PEREIRA, J. S.; SILVA, R. G. S. O ensino de geomorfologia na educação básica a partir do cotidiano do aluno e o uso de ferramentas digitais como recurso didático. Revista de Ensino de Geografia, Uberlândia, v. 3, n. 4, p. 69-79, 2012. 
RIBEIRO, S. C. Etnogeomorfologia sertaneja: metodologia aplicada nos sítios Farias e Santo Antônio, Barbalha/ CE. Revista Geonorte, Manaus; v. 1, n. 4, p. 408-420, 2012.

RIBEIRO, S. C.; MARÇAL, M. S.; CORRÊA, A. C. B. Etnogeomorfologia sertaneja - o conhecimento tradicional do produtor rural nordestino sobre o relevo e seus processos na sub-bacia do Rio Salgado/CE. GEOgraphia, Niterói, v. 17, n. 33, p. 205-224, 2015.

RIBEIRO, S. C. Etnogeomorfologia na Perspectiva da Gestão Ambiental e Aprendizagem na Educação Básica. Espaço Aberto, Rio de Janeiro, v. 6, n. 1, p. 175-190, 2016.

SOUZA, C. J. O. Ensino de geomorfologia: desafios na formação inicial. Revista de Geografia, Recife, v. 35, n. 4, p. 288-308, 2018.

SILVA, V. A.; ALMEIDA, A. L. S.; ALBUQUERQUE, U. P. Etnobiologia e Etnoecologia: pessoas ; natureza na América Latina. 1. ed. Recife: NUPEEA, 2010. 230p.

SCHNETZLER, R. S. Construção do conhecimento e ensino de ciências. Em Aberto, Brasília, v.11, n. 55, p. 17- 22, 1992.

TIMBANE, S. A.; AXT, M.; ALVES, E. O celular na escola: vilão ou aliado. Nuevas Ideas en Informática Educativa. TISE, Porto Alegre, v. 1 n. 1, p. 1-6, 2015.

TOLEDO, V. M.; BARRERA-BASSOLS, N. A Etnoecologia: uma ciência pós-normal que estuda as sabedorias tradicionais. Desenvolvimento e Meio Ambiente, Curitiba, v. 20, p. 31-45, 2009.

TORRES, E. C.; SANTANA, C. D. Geomorfologia no ensino fundamental: Conteúdos Geográficos e Instrumentos Lúdico-Pedagógicos. GEOGRAFIA, Londrina, v. 18, n.1, p. 233-246, 2009.

WILCOCK, D.; BRIERLEY, G.; HOWITT, R. Ethnogeomorphology. Progress in Physical Geography, Sydney, v. 37, n. 5, p. 573-600, 2013. 